\title{
An international review of occupant-related aspects of building energy codes and standards
}

O'Brien, William; Tahmasebi, Farhang; Andersen, Rune Korsholm; Azar, Elie; Barthelmes, Verena; Belafi, Zsofia Deme; Berger, Christiane; Chen, Dong; De Simone, Marilena; d'Oca, Simona

Total number of authors:

24

Published in:

Building and Environment

Link to article, DOI:

10.1016/j.buildenv.2020.106906

Publication date:

2020

Document Version

Early version, also known as pre-print

Link back to DTU Orbit

Citation (APA):

O'Brien, W., Tahmasebi, F., Andersen, R. K., Azar, E., Barthelmes, V., Belafi, Z. D., Berger, C., Chen, D., De Simone, M., d'Oca, S., Hong, T., Jin, Q., Khovalyg, D., Lamberts, R., Novakovic, V., Park, J. Y., Plagmann, M., Rajus, V. S., Vellei, M., ... Zhou, J. (2020). An international review of occupant-related aspects of building energy codes and standards. Building and Environment, 179, [106906].

https://doi.org/10.1016/j.buildenv.2020.106906

\section{General rights}

Copyright and moral rights for the publications made accessible in the public portal are retained by the authors and/or other copyright owners and it is a condition of accessing publications that users recognise and abide by the legal requirements associated with these rights.

- Users may download and print one copy of any publication from the public portal for the purpose of private study or research.

- You may not further distribute the material or use it for any profit-making activity or commercial gain

- You may freely distribute the URL identifying the publication in the public portal 


\section{An international review of occupant-related aspects of building energy codes and standards}

William O'Brien ${ }^{a, *}$, Farhang Tahmasebi ${ }^{b}$, Rune Korsholm Andersenc, Elie Azard, Verena Barthelmese, Zsofia Deme Belafi, Christiane Berger", DongChen ${ }^{h}$, MarilenaDe Simonei, Simona d'Ocai, Tianzhen Hongk, Quan Jin', Dolaana Khovalyge, Roberto Lambertsm, Vojislav Novakovicn, June Young Park', Manfred Plagmann" ${ }^{p}$, Vinu Subashini Rajus", Marika Velleir, Silke Verbruggens, Andreas Wagner, Eric Willemsi, Da Yanv, Jin Zhouw

a Department of Civil and Environmental Engineering, Carleton University, Canada

b UCL Institute for Environmental Design and Engineering, University College London, UK

c International Centre for Indoor Environment and Energy, Department of Civil Engineering, Technical University of Denmark, Denmark d Department of Industrial and Systems Engineering, Khalifa University, United Arab Emirates

e School of Architecture, Civil and Environmental Engineering (ENAC), Thermal Engineering for the Built Environment Laboratory (TEBEL), Switzerland

f Department of Building Services and Process Engineering, Budapest University of Technology and Economics, Hungary g Department of Building Physics and Building Ecology, TU Wien, Austria

h CSIRO Energy, Commonwealth Scientific and Industrial Research Organisation, Australia

i Department of Environmental Engineering (DIAm), University of Calabria, Italy

j Huygen Engineers \& Consultants BV, Netherlands

k Building Technologies and Urban Systems Division, Lawrence Berkeley National Laboratory, USA

I Department of Architecture and Civil Engineering, Chalmers University of Technology, Sweden

mDepartment of Civil Engineering, Federal University of Santa Catarina, Brazil

$\mathrm{n}$ Department of Energy and Process Engineering, Norwegian University of Science and Technology, Norway

- Department of Civil, Architectural and Environmental Engineering, The University of Texas at Austin, USA

p BRANZ, New Zealand

q Department of Systems and Computer Engineering, Carleton University, Canada

r LaSIE (UMR CNRS 7356), La Rochelle University, France

s Department Architecture and Urban Planning, Research Group Building Physics, Ghent University, Belgium

t Building Science Group, Karlsruhe Institute of Technology, Germany

$\checkmark$ School of Architecture, Tsinghua University, China

wDepartment of Civil Engineering, Monash University, Australia

\section{Abstract}

In light of recent research, it is evident that occupants are playing an increasingly important role in building energy performance. Around the world, a driving factor for how buildings are designed - and operated in some cases - is the local building codes. Yet, occupant-related aspects of building energy codes have traditionally been simple because: 1) occupants are often seen as a source of uncertainty that cannot be reconciled by current code methodologies and language, and 2) the codes have not kept up with the recent surge of interest and importance of occupants. This paper provides a review of 22 international building energy codes and standards by first comparing quantitative aspects and then analyzing rules and approaches mandated by the codes. The review of requirements for prescriptive and performance path requirements revealed a wide range of occupant-related values, approaches, and attitudes. For example, a key value such as occupant density varies by nearly a factor of three between countries' codes, which among other things underlines the need for development of locally tailored occupant behaviour models for future occupant-centric building performance standards and codes. Moreover, occupants are often referred to only implicitly; the level of optimism that occupants make energy-saving actions varies greatly; and, only a few codes address occupant feedback and system usability. Based on the findings, a set of initial recommendations for future building energy codes is made. The focus in this paper is offices, though the general recommendations are applicable to other building types.

\section{Introduction and literature review}

It is becoming widely accepted that building performance is increasingly sensitive to occupant behavior as the efficiency of building materials and systems improves and plug loads become an increasing part of energy end uses (Hoes, Hensen et al. 2009, Fouquet and Pearson 2012, Hafer 2017). In 
commercial/institutional and residential buildings alike, occupants have been shown to affect the energy use in architecturally-identical offices and homes by a factor of three or more (Gram-Hanssen 2010, Haldi and Robinson 2011, Hong and Lin 2013). These differences largely result from use of operable windows, plug-in equipment, lighting, shading devices, thermostats, and presence itself. Accordingly, the topic of occupant behavior in buildings has received a surge of research interest (Yan, Hong et al. 2017, Park and Nagy 2018), with several international projects coordinating the effort (IEA EBC Annex 66 and 79) (Wagner and O'Brien 2018, Yan and Hong 2018). Yet, with much of the research being fundamental and academic in nature, significant knowledge transfer efforts are needed to have an impact on the architecture, engineering, and construction (AEC) industry.

One of the most influential ways to improve the energy performance of buildings is through advancement of building codes (Evans, Roshchanka et al. 2017). Building energy codes can be used to enforce a minimum set of building energy efficiency requirements, such as envelope, HVAC, and lighting. Numerous studies have shown that building energy codes can achieve on the order of 5 to $20 \%$ energy savings for the building stock (Chirarattananon, Chaiwiwatworakul et al. 2010, Jacobsen and Kotchen 2013, Evans, Roshchanka et al. 2017).

There are two main approaches in most building codes: prescriptive and performance. Many codes and standards (e.g., ASHRAE 2016) allow users to choose one compliance path to follow. The prescriptive path is a checklist-style list of rigid requirements that is relatively straightforward to follow and enforce, but it lacks flexibility. For instance, it may not give credit for new technologies or novel design and operating strategies. The performance path of codes does not necessarily enforce individual requirements (e.g., R-value or HVAC efficiency), but rather places the ownness on the building owner to demonstrate that the overall energy performance will be better than an equivalent building (referred to as notional or reference building) with the minimum requirements of the prescriptive path. This is normally achieved through a detailed building model and annual simulations for the proposed and code-minimum equivalent buildings. The flexibility of the performance path, combined with advances in building performance simulation (BPS), have increased its popularity. For instance, it enables buildings to have architecturally desirable features (e.g. very large windows with a window-to-wall area ratio approaching 60 to $70 \%$ ) that would not be allowed by the prescriptive path. There is a general international transition towards performance-based codes (Evans, Roshchanka et al. 2017). A third path is available in many codes: the trade-off path is a model-less way to deviate somewhat from the prescriptive requirements through providing equivalent measures. As stated by NECB (NRC, 2017), "The trade-off options present an easy way to make small adjustments to the characteristics of the building without having to follow the whole-building performance route."

The widespread benefits of building energy codes are undeniable and widespread (lower environmental impact, lower energy bills, occupant health and comfort, energy resilience, safety, building longevity, etc.). However, building energy codes must ultimately be enforced by officials to fully realize these benefits (Aroonruengsawat, Auffhammer et al. 2012, Jacobsen and Kotchen 
2013). Non-compliance may be a result of designer negligence or intentional, knowing that officials are unlikely to enforce requirements (Misuriello, Penney et al. 2010). Methods of enforcement, stringency, and consequences of violations vary widely between jurisdictions (Laustsen 2008, Evans, Roshchanka et al. 2017). The current paper does not cover enforcement in depth, but it is ultimately a consideration for codifying requirements. Accordingly, balancing stringency and level of detail with ease of use by designer and code officials alike is critical. Performance-based energy codes are particularly challenging to enforce because of the number of inputs in BPS tools. For example, the National Energy Code of Canada for Buildings (NRC2017) states the following question as a consideration for amendments in its preamble: "Will enforcement agencies be able to enforce the requirement?" Thus, consideration of enforcement is particularly important regarding the way occupants are treated in building energy codes, relative to the state-of-the-art in occupant modeling research. For instance, how can a building designer be accused if an occupant behaves unexpectedly?

As noted by Evans, Roshchanka et al. (2017), few studies have comprehensively reviewed building codes at the international level. Even fewer have examined specific aspects of buildings codes, with few exceptions such as Perez-Lombard, which is focused on HVAC-related requirements in building codes (PérezLombard, Ortiz et al. 2011). And notably, none of the reviews have focused on occupant-related aspects, perhaps due to the relatively recent interest in the topic.

In contrast to wall assemblies, lighting technology, and HVAC systems, which can be specified in a quantitative way and later enforced by code officials - often using tangible evidence (e.g., drawings, specifications, product labels), occupantrelated aspects of the building codes are significantly more complex. Commonly, the occupants are unknown during the building design and code compliance process. Thus, it is typically not appropriate or possible to specify occupant behavior in a similar way to other building requirements. Nevertheless, occupants are playing an ever-growing role in building performance. Thus, they can no longer be neglected or otherwise minimized by building codes.

To date the occupant-related aspects of building codes are quite simplistic and treated more like a boundary condition (much like weather) than as active participants in the building (Deru, Field et al. 2011, Feng, Yan et al. 2015). However, in contrast to weather, building design can influence how buildings behave (O'Brien and Gunay 2015). The most common way to specify occupants in the performance path of building codes is through hourly schedules. O'Brien, Gaetani et al. (2016) found that many modellers use building code occupantrelated schedules, even if the code allows flexibility because modelers lack better information at the time of design. Through a workshop of energy modellers, Abuimara, O'Brien et al. (2018) reported that modellers tend to use defaults/code assumptions about occupants to avoid liability, even if they know these values are unrealistic.

Though modellers seem to have doubts over the current approach to require occupants to be modelled identically in the reference and proposed building models, few papers have looked at building codes related to occupants. O'Brien et al. (2019) showed that the current occupancy schedules for offices in North 
American codes - which are near-full capacity during weekdays - may cause design teams to overlook the benefit of occupancy-adaptive building controls (namely, demand-controlled ventilation and occupancy-controlled lighting with small lighting control zones). Gilani et al. (2016) showed that optimal window area is significantly affected by the assumptions made about occupants, thus demonstrating the importance of modelling appropriate and realistic occupant behavior. Besides, an overestimated level of occupancy may also lead to an overestimation of occupant actions, since occupants are necessarily required for adaptive actions to be made.

The objective of this paper is to first present a comprehensive international review of the occupant-related aspects and considerations of building energy codes, and then to make recommendations to code committees and other policymakers around the world. While occupants are quite central in comfortrelated building standards (e.g., ASHRAE Std. 55, EN 15251, ISO 7730), this paper is restricted to energy codes and standards. The paper starts with the data collection and analysis methodology. Both quantitative and qualitative aspects of 22 international building codes are reviewed. Next, the occupant-related features of the codes are compared. Finally, based on these findings, recommendations for improvements in future building codes are made.

\section{Methodology}

The review process was initiated by contacting participants of IEA EBC Annex 79 to request their assistance in providing information about their national building codes. Among participants' contacts in other countries, 22 participants provided information on 23 regions (mostly whole countries except UAE) building energy codes. The countries are listed in Table 1 and shown in Figure 1. Data were collected using a template on an online spreadsheet tool such that all participants could see the results. The participants were required to translate the collected data into English; this is justified on the basis that they generally perform research in English and have advanced technical knowledge of buildings and energy codes. The data collection was formalized into two phases described next, after which the data was analyzed both through a quantitative and qualitative lens. 


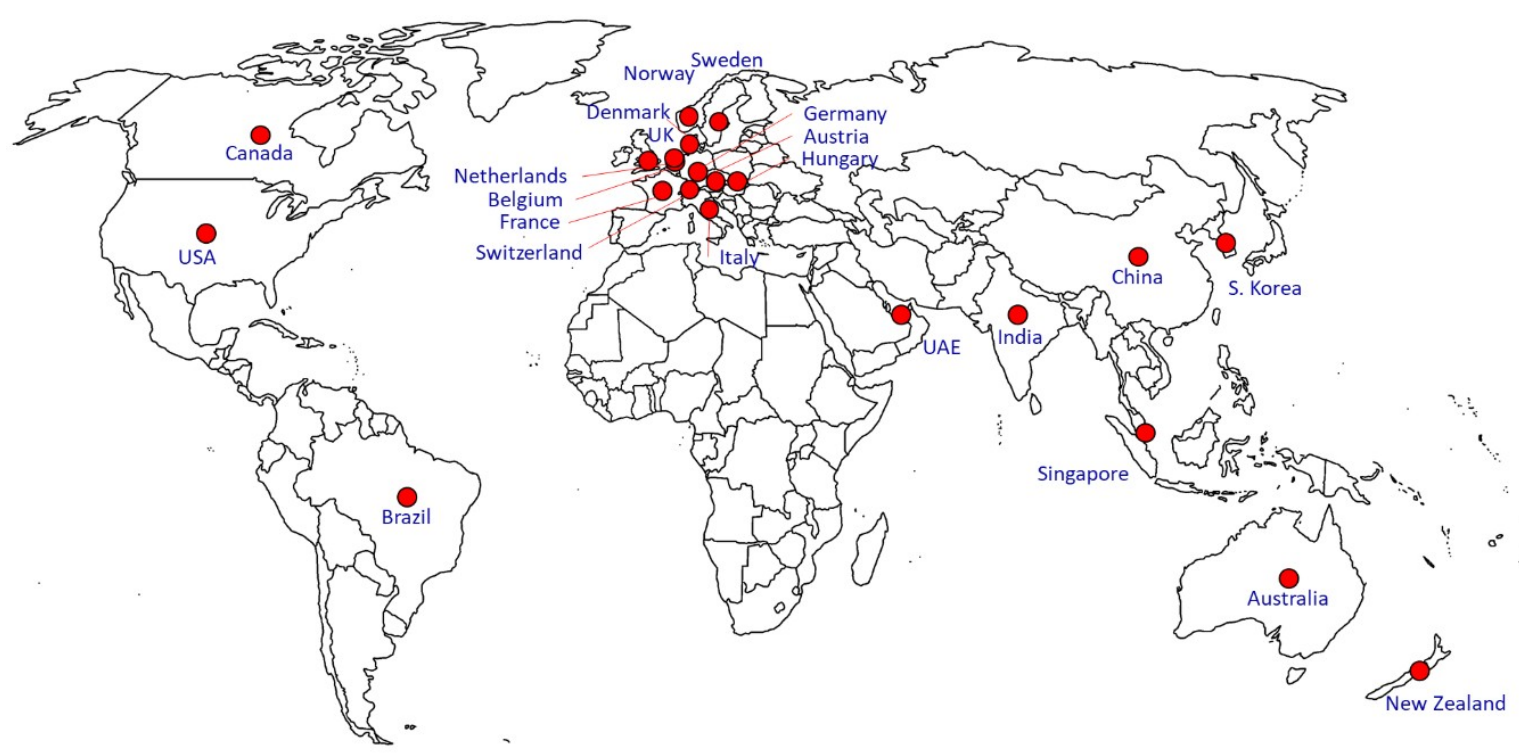

Figure 1: Map of countries included in the building energy code review

Table 1: The participating countries and the corresponding building code or standard that was reviewed in this paper

\section{Country Code reviewed}

Australia National Construction Code (NCC) 2016 Volume One

Austria ÖNORM B 8110

Belgium Determination method of the level of primary energy use in non-residential buildings (Annex $\mathrm{VI}$ )

INI-C Método para a avaliação da eficiência energética com base em energia primária de edificações comerciais, de

Brazil serviços e públicas

Canada

National Building Energy Code for Canada

China

Design standard for energy efficiency of public buildings (GB50189-2015)

Denmark bygningsreglementet

France Méthode de calcul Th-BCE 2012

Germany Energy Saving Ordinance (EnEV)

Hungary European Performance of Buildings Directive (EPBD), EUROPEAN COMMISSION, 2002

Hungarian transposition of EPBD: Ministerial Decree No.

7/2006. (V. 24.) TNM on the establishment of energy characteristics of buildings

India

Energy Conservation Building Code

UNI/TS 11300-1:2014 Prestazioni energetiche degli edifici Parte 1: Determinazione del fabbisogno di energia termica dell'edificio per la climatizzazione estiva ed invernale UNI/TS 11300-1:2014 Energy performance of buildings Part

Italy 1: Evaluation of energy need for space heating and cooling 
Netherlands

New Zealand

Norway

Singapore

South Korea

Sweden

Switzerland

UAE - Dubai

(UAE-2)

UAE - Abu

Dhabi (UAE-

1)

UK

USA
NEN7120:2012 Energieprestatienormering Gebouwen

New Zealand Building Code (NZBC) and Compliance

Documents

Technical specification SN/TS 3031:2016: Energy

Performance of Buildings, Calculation of Energy Needs and Energy Supply

Building Control (Environmental Sustainability) Regulations 2008 (BCR ES:2008), and Green Mark for Non-residential Buildings:2015 (GM NRB:2015), both issued by the Building and Construction Authority (BCA)

Building Design Criteria for Energy Saving (BDCES): Standard for intelligent building, Standard for HVAC design Boverkets föreskrifter och allmänna råd om fastställande av byggnadens energianvändning vid normalt brukande och ett normalår (The Swedish National Board of Housing, Building and Planning's regulations and general advice on the determination of the building's energy use during normal use and a normal year); Sveby brukarindata kontor (Sveby standard for the energy use in buildings - occupant input data for offices) [note: it is a voluntary guideline]

SIA 380/1:2016 - Heizwaermebedarf + SIA 2024:2015

Raumnutzungsdaten fuer die Energie- und Gebaeudetechnik

Al Sa'fat Dubai Green Building Evaluation System

The Pearl Rating System for Estidama

National Calculation Methodology (NCM) Modelling Guide in support of the 2013 Edition of the Building Regulations Approved Document L2A (Conservation of fuel and power in new buildings other than dwellings)

ASHRAE 90.1 (2016), IECC Commercial Building models

\subsection{Data collection}

Phase 1 involved collecting quantitative data focused on schedules and densities for occupancy, lighting, equipment, and other internal heat gains. Further information was collected on desk illuminance requirements, ventilation requirements, heating and cooling setpoint and nighttime setbacks, operable windows, and window shades. Together these represent the common specifications in model/performance-oriented paths of the reviewed building codes.

Phase 2 focused on both prescriptive and modelling requirements of building codes that were provided in the form of sentences. Contributors were asked to both extensively search for keywords (e.g., occupant, user, occupancy) and read their respective code to seek implicit references to occupants (e.g., how window shades should be assumed to be used and requirements for manual modes of building systems). Contributors were required to provide at least five instances 
of occupant-related code requirements (many provided 10 or more to yield a total of 160 items); thus, collected data is not exhaustive but provides a wide spectrum of the sorts of occupant-related code requirements and the nature of their specification.

\subsection{Purpose of the codes}

All the studied codes are indented to be used for energy performance compliance or rating. While in some cases the codes may enforce specific aspects of building design and operation in a prescriptive manner, all the codes, except for the one from Singapore, adopt a performance-based compliance method. Most of the codes performance target is based on secondary or primary energy use. However, the codes of Italy and Austria are based on heating and cooling energy demand. In England's code a target emission rate is defined and the French code exploits a maximum operative temperature target for a summer day in addition to the energy targets. UAE codes introduce both energy and water performance targets.

\subsection{Data analysis}

Phase 1 is focused on a direct comparison of occupant-related design values and schedules. It compares and contrasts the codes in terms of the magnitude of the values and the granularity of assumptions and modeling methods.

Because the collected data for Phase 2 is not comprehensive but rather based on examples, the analysis was primarily qualitative. When analyzing the data, the following questions were considered:

- What aspects of buildings are considered in the context of occupants (e.g. lights)?

- What terms do building codes use to refer to, or imply, occupants?

- How simple or complex are occupants treated?

- How optimistic or pessimistic are building codes about occupant behavior and its ability to reduce energy use or improve comfort?

- What are the most notable code requirements that should be considered elsewhere?

Each of these questions is systematically answered, relying on specific examples, where applicable.

\section{Results}

\subsection{Phase 1: Results of quantitative code requirement analysis}

This section summarizes and compares the quantitative occupant-related assumptions and recommendations obtained from the 22 countries' building energy codes.

\subsubsection{Occupancy density and use of lights, equipment and hot water}

In the absence of an explicit consideration of occupants' interactions with environmental control devices such as thermostats, shades, luminaires and windows, assumptions concerning people density, lights and equipment power along with hot water use are the key elements that implicitly represent occupant energy-related behaviour in the studied codes. In most of the codes these time- 
varying parameters are defined with a maximum design value (addressed in the present section) and an associated schedule (see section 3.1.2).

The data obtained from the 22 countries' building energy codes, above all, reveals that the design values for the aforementioned aspects of occupant behaviour, which are given in Table 2 , differ considerably across the codes. Figure 2 and Figure 3 demonstrate that occupancy and lighting power density vary by nearly a factor of three between countries. The variation is more significant for equipment use. This wide range can be seen in Figure 4, as Singapore's code considers $16 \mathrm{~W} / \mathrm{m}^{2}$ for equipment power density, while Austrian code defines an equipment load of not more than $1.3 \mathrm{~W} / \mathrm{m}^{2}$.

Besides the variations in terms of the magnitude of these parameters, the studied codes also reveal different approaches to establish the assumptions with regard to lighting power. While the majority of codes have tried to provide a "reasonable" single value for the lighting power density in office buildings, Swedish code has explicitly given two different values for efficient and very efficient lighting. The codes used in England and Germany deploy simplified calculation procedures to derive the lighting power density based on zone geometry and luminaire efficacy. Hungary code also explicitly considers a reduction factor of 0.7 in case daylight, occupancy or movement sensors are installed. ASHRAE 90.1 also reflects the requirement for occupancy sensors by a modification in lighting profiles such that the hourly fraction of lighting density reaches 0.65 at maximum. In this regard, there seems to be a need for further explicit considerations of manual and automated control modes and emerging lighting technologies.

As for hot water use, the codes use a number of different units, which limits the possibility of a straightforward comparison. More precisely, occupant use of hot water has been estimated in terms of the amount of water or heating energy and has been normalized based on floor area or number of occupants. It is worth mentioning that, as opposed to occupant use of light and equipment that is commonly represented with a power value and an accompanying hourly schedule, hot water use is mainly given as an aggregated value of energy or water volume over a day or a year.

Table 2: Occupant-related assumptions concerning presence, use of lights, equipment and hot water in office buildings found in the international building energy codes. The units are as specified in the headers unless stated otherwise.

\begin{tabular}{|c|c|c|c|c|}
\hline Country & $\begin{array}{c}\text { People density or } \\
\text { heat gain } \\
{\left[\text { person } / \mathrm{m}^{2}\right]}\end{array}$ & $\begin{array}{c}\text { Lighting power } \\
\text { density } \\
{\left[\mathrm{W} / \mathrm{m}^{2}\right]}\end{array}$ & $\begin{array}{c}\text { Equipment } \\
\text { power } \\
\text { density } \\
{\left[\mathrm{W} / \mathrm{m}^{2}\right]}\end{array}$ & $\begin{array}{c}\text { Hot water } \\
\text { consumption } \\
{\left[\mathrm{l} /\left(\mathrm{d} . \mathrm{m}^{2}\right)\right]}\end{array}$ \\
\hline AUS & 0.10 & $9.0,7.0^{1}$ & 15.0 & $4.0 \mathrm{l} /(\mathrm{d} . \mathrm{person})$ \\
\hline AUT & $1.7 \mathrm{~W} / \mathrm{m}^{2}$ & $25.76 \mathrm{kWh} /\left(\mathrm{m}^{2} . \mathrm{a}\right)$ & 1.3 & $9.0 \mathrm{Wh} /\left(\mathrm{m}^{2} . \mathrm{d}\right)$ \\
\hline BEL & 0.07 & 6.0 & 3.0 & $5.0 \mathrm{MJ} /\left(\mathrm{m}^{2} . \mathrm{a}\right)$ \\
\hline BRA & 0.10 & 14.1 & 9.7 & - \\
\hline CAN & 0.04 & 8.8 & 7.5 & $90 \mathrm{~W} /$ person \\
\hline CHE & 0.07 & 15.9 & 7.0 & $3.0 \mathrm{l} /(\mathrm{d}$. person $)$ \\
\hline CHN & 0.10 & 9.0 & 15.0 & $5-10$ \\
\hline DEU & 0.07 & $\mathrm{n} / \mathrm{a}^{2}$ & 7.1 & 0.70 \\
\hline
\end{tabular}

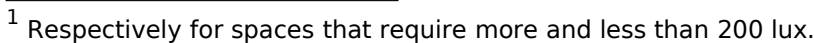




\begin{tabular}{|c|c|c|c|c|}
\hline DNK & $0.044^{3}$ & 11.0 & 6.0 & 0.27 \\
\hline ENG & 0.11 & $n / a^{4}$ & 11.8 & 0.20 \\
\hline FRA & 0.10 & - & 16.0 & 0.18 \\
\hline HUN & $n / a^{5}$ & $11.0 \mathrm{kWh} /\left(\mathrm{m}^{2} . \mathrm{a}\right)^{6}$ & $\mathrm{n} / \mathrm{a}$ & $9.0 \mathrm{kWh} /\left(\mathrm{m}^{2} . \mathrm{a}\right)$ \\
\hline IND & 0.05 & 10.0 & - & - \\
\hline ITA & $0.05^{7}$ & - & 15.0 & 0.2 \\
\hline KOR & 0.05 & $15.8^{8}$ & $12.9^{8}$ & $0.237^{8}$ \\
\hline NLD & 0.06 & - & 4.0 & $65 \mathrm{l} /\left(\mathrm{m}^{2} . \mathrm{d}\right)$ \\
\hline NOR & $50 \mathrm{Wh} /\left(\mathrm{m}^{2} . \mathrm{d}\right)$ & 9.6 & 13.1 & $19.22 \mathrm{Wh} /\left(\mathrm{m}^{2} . \mathrm{d}\right)$ \\
\hline NZL & 0.06 & 12.0 & 8.1 & - \\
\hline SGP & $0.1,0.06^{9}$ & 12.0 & 16.0 & - \\
\hline SWE & 0.05 & $7.6,3.2^{10}$ & $11.6^{11}$ & $2 / n \mathrm{kWh} /\left(\mathrm{m}^{2} \cdot a\right)^{12}$ \\
\hline UAE-1 & 0.05 & 8.7 & 8.1 & - \\
\hline UAE-2 & 0.05 & 10.0 & - & - \\
\hline USA & 0.05 & 10.8 & 8.1 & $5.0 \mathrm{l} /$ (d.person) \\
\hline
\end{tabular}

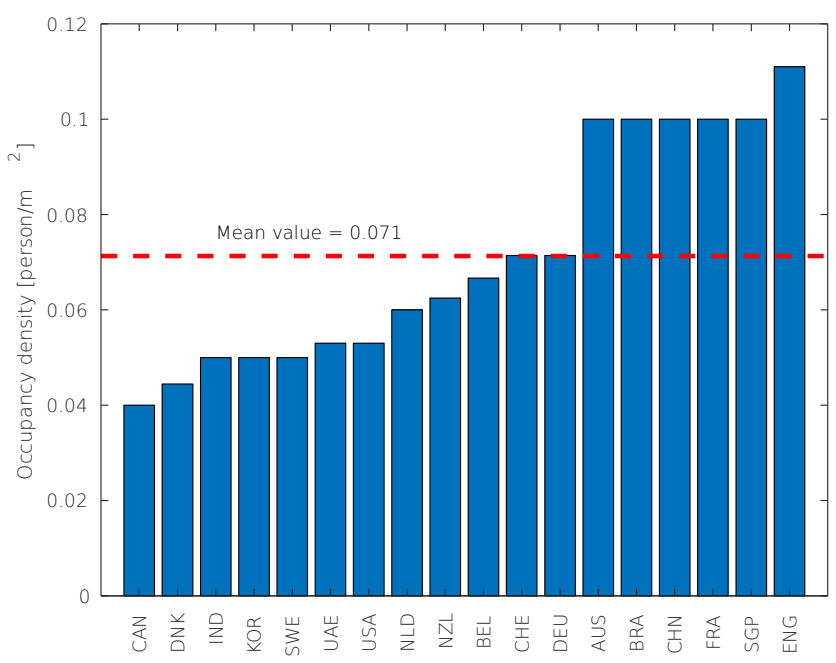

Figure 2: The values of occupancy density for offices given in international building energy codes

\footnotetext{
2 Lighting power is calculated based on office geometry and other parameters according to a simplified calculation routine referred to as efficiency procedure.

${ }^{3}$ Derived based on stated values of $4 \mathrm{~W} / \mathrm{m}^{2}$ for internal heat gain by occupants and $90 \mathrm{~W} /$ person for metabolic rate.

4 Power density is calculated based on lighting with efficacy of 60 luminaire lumens per circuit-watt and a regression-based function for zone geometry.

${ }^{5}$ Internal heat gains from people, lighting and equipment are not specified, only a single value of $7 \mathrm{~W} / \mathrm{m}^{2}$ is given for all internal heat gains.

6 It can be multiplied by 0.7 in case daylight, occupancy or movement sensors are installed.

7 The code offers five classes of occupant density for non-residential buildings.

8 Based on a research effort on reference building energy models for South Korea (Kim et al. 2017).

${ }^{9} 0.1$ for admin/general office room, 0.06 for director/manager room.

107.6 for efficient lighting, 3.2 for very efficient lighting.

11 The given value is based on estimated average power of medium level.

$12 \eta$ is the annual efficiency of hot water production.
} 


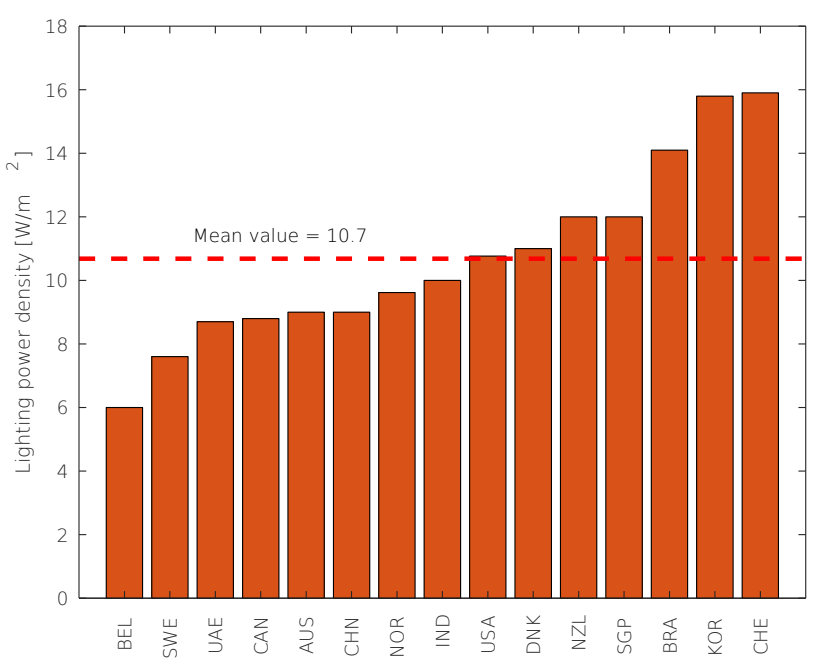

Figure 3: The values of lighting power density for offices given in international building energy codes

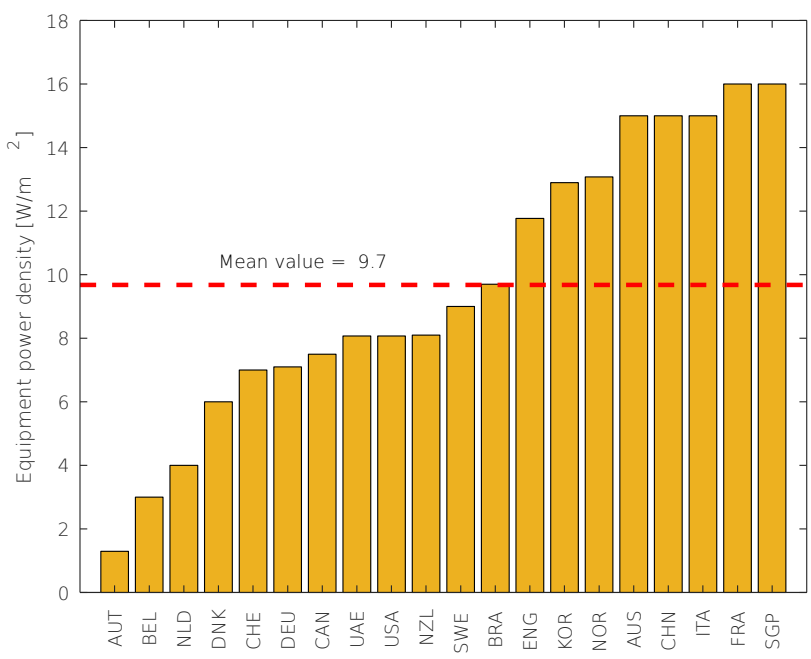

Figure 4: The values of equipment power density for offices given in international building energy codes

\subsubsection{Hourly schedules for occupancy and use of lights and equipment}

Among the 22 studied codes, 10 countries' codes (namely, Australia, Brazil, Canada, China, England, France, India, New Zealand, Singapore and USA) are based on dynamic performance simulation - or at least have the option to use it for compliance. These codes provide hourly schedules for occupancy, use of lights and equipment (and in some cases for service hot water). Switzerland and Norway also provide such hourly profiles, even though they conduct monthly heat balance calculations. The other codes, which are based on a monthly calculation frequency (for example Germany and Denmark), only consider a Boolean pattern for nominal working hours and otherwise. Figure 5 to Figure 7 illustrate the weekday schedules for occupancy density, lighting and equipment power obtained from those codes, which either offer a dynamic simulation path or explicitly consider hourly patterns in working days. Tables A.1, A.2 and A.3 provides the hourly values of these schedules. 
The collected hourly profiles suggest that the cross-country variety in schedules is not as considerable as design values. Nonetheless, there are still a number of notable differences between the codes in terms of the hourly profiles associated with occupants, which are likely to result from different working cultures in the countries. For example, as illustrated in Figure 7, one can see the variety in view of the equipment base load outside nominal working hours. As it can be seen in Table A.3, even among the simulation-based codes, this can vary from zero in case of Brazil to 20 percent of design value in case of Canada. Notably, the transition to and from nominal working hours is also different among the codes. While in the majority of simulation-based codes, it takes one to two hour to reach maximum occupancy in the morning, the codes of Brazil, New Zealand and Singapore jump from fully vacant to fully occupied, which has implications for heating and cooling demand estimations. Similarly, while in a number of codes there is a clear separation between the nominal working time and following hours, in other codes the occupancy and associated load lasts until late evening. In a rather odd case, England's equipment schedule used in this study (referred to as Office_OpenOff_Equip_Wkdy in NCM database) suggests 100 percent equipment load from 17:00 to 19:00, while according to the corresponding occupancy profile (referred to as Office_OpenOff_Occ_Wkdy in NCM database) people density is assumed to be 50 and 25 percent in this period.

Another noteworthy difference is the way in which the codes treat lunch break. A number of countries' codes (such as Australia, Brazil, New Zealand and Singapore) do not suggest any reduction in terms of occupancy density and associated light and plug loads for this period of the day. However, USA and India codes, for example, suggest a reduction of 45 percent of maximum occupancy density during lunch break. India code maintains this reduction for the lighting load as well.

Aside from the abovementioned differences, it is important to note that all the occupancy profiles reach 90 to 100 percent of the maximum occupancy density. While previous studies (O'Brien, Gunay et al. 2017, Tahmasebi and Mahdavi 2017) underlined this as an overestimation of actual occupant patterns, the codes unanimously adopt this conservative (perhaps system-sizing oriented) approach.

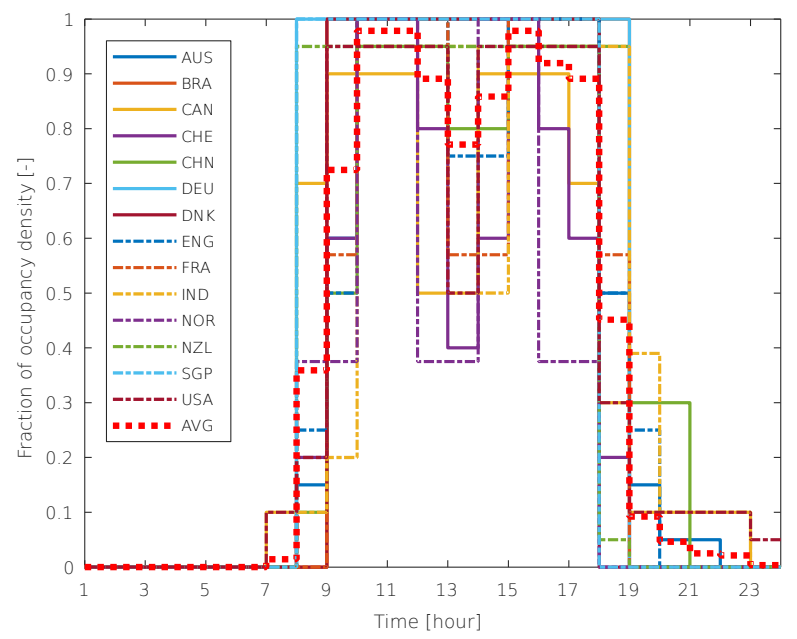


Figure 5: The schedules of weekday occupancy for offices given in international building energy codes together with the average schedule (AVG)

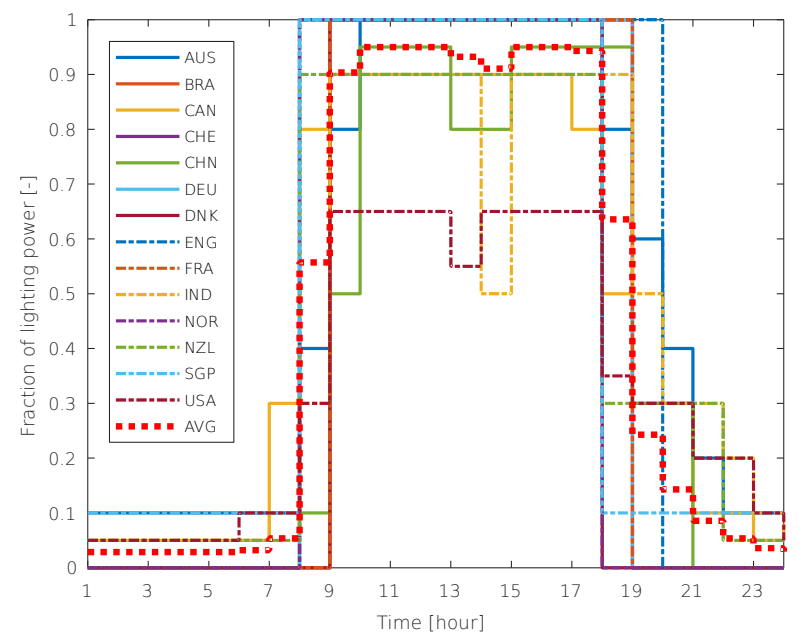

Figure 6: The schedules of weekday lighting power for offices given in international building energy codes together with the average schedule (AVG)

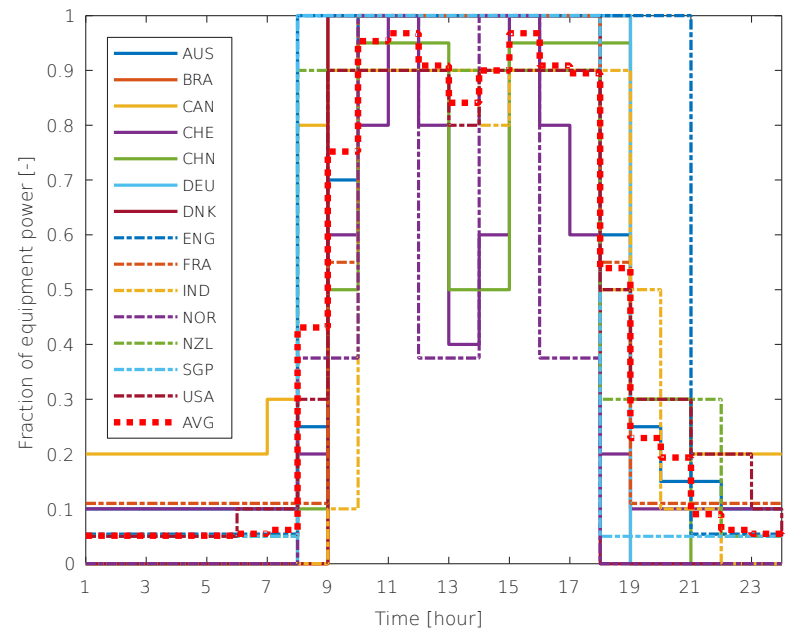

Figure 7: The schedules of weekday equipment power for offices given in international building energy codes together with the average schedule (AVG)

\subsubsection{Lighting level, ventilation rate, setpoint and setback temperatures}

While the studied building energy codes, above all, treat occupants as sources of internal heat gain for the heat balance calculations, to some degree they consider the occupant needs in terms of indoor environmental conditions. Main examples of such attention are recommendations with regard to ventilation rate and the lighting level (for workplane) along with the heating and cooling setpoint and setback temperatures, which implicitly consider occupant thermal preferences (see Table 3). This, however, does not constitute a consideration of the interactions between occupant and control system as a result of different environmental conditions.

The 22 countries considered in the study mainly recommend a desk illuminance of 300 to 500 lux. The French building code, however, prescribes 120 lux as the 
minimum desk level illuminance, which given the current screen-based nature of office activities can potentially reduce electrical energy use without compromising occupant visual comfort. Among the codes that recommend a ventilation rate per person, this varies from $6 \mathrm{l} /($ s.person) in Belgium to 11 I/(s.person) in Italy.

While none of the codes explicitly considers occupants interactions with thermostats, cooling setpoint temperature varies from $22 \pm 1.5^{\circ} \mathrm{C}$ in New Zealand to $28{ }^{\circ} \mathrm{C}$ in South Korea and heating setpoint ranges from $18{ }^{\circ} \mathrm{C}$ in Australia and India to $22{ }^{\circ} \mathrm{C}$ in Austria, Canada and England. Many codes do not consider a setback temperature (no value in the corresponding columns in Table 3 ), while others represent an automated adjustment of the setpoint for some degrees or do no assume any heating or cooling outside working hours (specified as off in the corresponding columns in Table 3).

A number of countries has further considerations for setpoint and setback temperatures. For example, Belgium code considers a temperature setback only in low inertia buildings. France code offers two heating setback temperatures, namely $16{ }^{\circ} \mathrm{C}$ for off-periods shorter than 48 hours and $7{ }^{\circ} \mathrm{C}$ for off-periods longer than 48 hours. Singapore code also considers two cooling setpoints, $23{ }^{\circ} \mathrm{C}$ for zone for solar gain and $25{ }^{\circ} \mathrm{C}$ otherwise.

Table 3: Occupant-related recommendations and assumptions concerning lighting level, ventilation rate, heating and cooling setpoint and setback temperatures. The units are as specified in the headers unless stated otherwise.

\begin{tabular}{|c|c|c|c|c|c|c|}
\hline Country & $\begin{array}{c}\text { Recommende } \\
\text { d desk } \\
\text { illuminance } \\
{[\text { lux] }}\end{array}$ & $\begin{array}{c}\text { Recommende } \\
d \text { ventilation } \\
\text { rate } \\
{[\mathrm{l} /(\mathrm{s} . \mathrm{person})]}\end{array}$ & $\begin{array}{c}\text { Cooling } \\
\text { setpoin } \\
\mathrm{t} \\
{[\mathrm{C}]}\end{array}$ & $\begin{array}{c}\text { Heating } \\
\text { setpoin } \\
\mathrm{t} \\
{[\mathrm{C}]}\end{array}$ & $\begin{array}{c}\text { Cooling } \\
\text { setback } \\
{[\mathrm{C}]}\end{array}$ & $\begin{array}{c}\text { Heating } \\
\text { setback } \\
{[\mathrm{C}]}\end{array}$ \\
\hline AUS & 320 & 10 & 26.0 & 18.0 & off & off \\
\hline AUT & 380 & $1.051 / \mathrm{h}$ & 26.0 & 22.0 & off & off \\
\hline BEL & 500 & 6 & 25.0 & 21.0 & $28^{13}$ & $15^{13}$ \\
\hline BRA & 500 & 7.5 & 24.0 & - & off & - \\
\hline CAN & 400 & 8.5 & 24.0 & 22.0 & off & 18.0 \\
\hline CHE & 500 & 10 & 26.0 & 21.0 & off & off \\
\hline CHN & 300 & 8.33 & 26.0 & 20.0 & off & off \\
\hline DEU & 500 & $1.8 \mathrm{I} /\left(\mathrm{s} . \mathrm{m}^{2}\right)$ & 24.0 & 21.0 & off & 17.0 \\
\hline DNK & 300 & 7 & 25.0 & 20.0 & off & - \\
\hline ENG & 400 & 10 & 24.0 & 22.0 & off & 12.0 \\
\hline FRA & $120^{14}$ & 7 & 26.0 & 19.0 & 30 & $16,7^{15}$ \\
\hline HUN & - & 7 & 26.0 & 20.0 & - & - \\
\hline IND & $300-500$ & 8.5 & 26.0 & 18.0 & - & 12 \\
\hline ITA & 300 & 11 & 26.0 & 20.0 & - & - \\
\hline KOR & - & 8.05 & 28.0 & 20.0 & - & - \\
\hline NLD & - & $1.3 \mathrm{I} /\left(\mathrm{s} . \mathrm{m}^{2}\right)$ & 24.0 & 20.0 & off & 18.0 \\
\hline NOR & - & $1.94 \mathrm{I} /\left(\mathrm{s} . \mathrm{m}^{2}\right)$ & 24.0 & 21.0 & - & 19.0 \\
\hline NZL & 400 & 10 & $22 \pm$ & $21 \pm$ & - & - \\
\hline SGP & 500 & $0.6 \mathrm{I} /\left(\mathrm{s} . \mathrm{m}^{2}\right)^{16}$ & 23,2517 & - & off & - \\
\hline
\end{tabular}

\footnotetext{
${ }^{13}$ The given value is for low inertia buildings. For high inertia buildings no heating or cooling setback temperature is assumed.

14 This is the minimum desk illuminance prescribed by the French Labour Code.

1516 for off periods less than 48 hours, 7 for off periods more than 48 hours.

${ }^{16}$ Maximum of $0.6 \mathrm{l} /\left(\mathrm{s} . \mathrm{m}^{2}\right)$ and $5.5 \mathrm{l} /(\mathrm{s}$.person).

1723 for zones with solar gain, 25 for other zones.
} 


\begin{tabular}{|c|c|c|c|c|c|c|}
\hline SWE & - & $1.3 \mathrm{I} /\left({\left.\mathrm{s} . \mathrm{m}^{2}\right)}^{2}\right.$ & 23.0 & 21.0 & off & off \\
\hline UAE-1 & 250 & 8.5 & 23.9 & - & 26.7 & - \\
\hline UAE-2 & 400 & 8.5 & 24.0 & - & - & - \\
\hline USA & $300-500$ & 8.5 & 23.9 & 21.1 & 26.7 & 15.6 \\
\hline
\end{tabular}

\subsection{Phase 2: Results of qualitative code requirements}

This section compares and contrasts the countries' codes regarding how occupant-related requirements are specified and the underlying philosophies. In some cases, exemplary excerpts are provided. The results are presented according to the questions in the Methodology section. For readability, the country is named rather than the specific building code name as per Table 1. In total, 167 examples were provided from the 22 countries' codes. Because these examples are non-exhaustive, quantitative analysis could not be performed.

\subsubsection{What aspects of buildings are considered in the context of occupants?}

The vast majority of the collected occupant-related code requirements involve HVAC equipment, lights, and window blinds/shades. Other occasional mentions include escalators and moving sidewalks, water use, occupant feedback (e.g. energy dashboard), and plug loads/receptacles. Very few requirements address details of manual systems, such as usability, nature of interface, required feedback to occupants, etc.

\subsubsection{What terms do building codes use to refer to, or imply, occupants?}

Overall, there is minimal explicit mention of occupants in the building codes reviewed. Numerous co-authors stated that they struggled to find just five mentions of occupants in their respective building energy code. Most of the occupant-related requirements relate to whether the building is occupied or not, occupancy sensors, and the degree to which building systems (HVAC and lighting, primarily) should be manual or automated. For example, many countries' codes specify that certain HVAC equipment (e.g., air conditioners) or lighting must be capable of being manually turned off or adjusted. The lack of explicit mention of occupants is likely rooted in the fact that building codes specify design and technology requirements rather than occupant requirements.

\subsubsection{How simple or complex are occupants treated?}

In contrast to the leading literature (e.g., Yan and Hong 2018), all reviewed building energy codes treat occupants in very simplistic ways - though to varying degrees of complexity. The predominant methods are listed below, followed by examples and discussion.

Assume the system (e.g., window shade) is not used at all. This method is particularly common for blinds; according to the building codes in Canada, India, New Zealand, and possibly others, blinds shall not be modelled (i.e., they are modelled as fully open). This may either because shade use is considered too uncertain or reliant on occupants or because shade system selection is not considered part of the code - both of which are unfortunate. Models to predict 
shade use are relatively mature and shade fabric selection is important for solar gains control and visual comfort (Reinhart 2004, IESNA 2012).

Assume the system is partially used. Recognizing that the above assumption is unrealistic as per numerous field studies (Fabi, Andersen et al. 2012, Van Den Wymelenberg 2012), several codes use a more typical and moderate approach. For the French code, during occupancy, shades are assumed $50 \%$ closed even if they are automated (manual overrides are also required). Similarly, Hungary requires that the mean properties for shades open and closed be used to model windows. The USA does the same for manuallycontrolled dynamic glazing (e.g., electrochromic windows). In Austria, the code allows users to decide whether occupants predictively or reactively adjust shades to address thermal discomfort. In the former case, the shade is assumed to be $50 \%$ closed, whereas the former is 0.25 . Sweden assumes shades are $71 \%$ closed.

\section{Provide fixed credit depending on the level of manual or automation of} systems (e.g. lighting). Numerous codes (e.g. Australia, Norway, Singapore, USA, Canada) give credit through prescriptive and/or performance paths to motion sensors that control lighting. Such credit is normally assigned as a decrement to the full lighting energy or power density. Belgium gives credit to annual lighting energy if a control system is present; however, it gives four times as much credit for automatic control (40\%) versus manual switching (10\%). Australia allows a $30 \%$ reduction in modelled lighting power density if a motion detector is linked to a zone of three to six luminaires and $45 \%$ reduction if it is one or two luminaires. Norway gives $20 \%$ credit if lighting is automatically controlled by daylight or occupancy.

Schedules and densities for the performance path. As evident from Phase 1 , schedules and densities are a common approach to specify occupancy and behavior for performance paths of codes. However, the flexibility of modifying schedules varies widely. For example, for Canada, India, US, the schedules can be modified if better information is available, but all values must be equal for the reference and design buildings. In fact, NECB states the default schedules should only be used if "more accurate information is not available". In contrast, New Zealand's code requires that default values be used unless a different schedule can be justified as being likely for the building's life. NECB also states "the reference building's operating schedules shall be modeled as being identical to those determined for the proposed building". For the American and Canadian codes, the schedules of the proposed building can only differ from the reference building schedules if used to model efficiency measures (e.g., automated lighting controls)

Rule-based operation of equipment. Relatively few codes have this more advanced form of occupant modeling, where occupant behavior depends on indoor or outdoor conditions. For the French code, occupants are assumed to keep the windows open even if the outdoor air temperature is higher than the indoor air temperature. Interestingly (and quite realistically (Goins, Chun et al. 2013)), window opening is assumed to be affected by noise, depending on the nature of, distance to, and obstruction of the noise source. In the American code's building envelope trade-off option, shades are assumed to be closed when the transmitted luminous intensity is exceeds $2000 \mathrm{~cd} / \mathrm{m}^{2}$ or the direct solar 
transmitted energy exceeds $95 \mathrm{~W} / \mathrm{m}^{2}$; they then remain closed for the rest of the day (which incidentally corresponds to the Lightswitch-2002 model (Reinhart 2004)). In contrast, for the French code, manual shade positions are assumed to vary linearly with the incident light and depending on the type of shade (shutter, roller blind, venetian blind), on the season (winter, mid-season and summer), on the indoor air temperature in the previous time step and on the wind speed (for the case of venetian blinds). France also assumes lights are controlled linearly with daylight levels. The English code requires the reference building to have natural ventilation modelled such as to yield up to 5 air changes per hour if the indoor temperature exceeds the heating setpoint by $1 \mathrm{~K}$. This requirement is intended to produce a neutral effect that is neither overly negative or beneficial. The Danish code is the only reviewed requirement with a hysteresis: for manually-controlled lighting, it is assumed that occupants turn on lights at a daylight illuminance level 200 lux above the lighting requirement and that they turn them off if daylight 200 lux above that.

\subsubsection{How optimistic or pessimistic are building codes about occupant behavior and its ability to reduce energy use or improve comfort?}

The level of implied or explicit optimism or pessimism of occupants varies greatly between countries. Some countries credit occupants for behaving in ways that improve comfort or energy performance, while others take a more pessimistic approach. To some extent, this range is appropriate considering the severity of the climates they cover.

Several codes provide explicit statements on their philosophy regarding occupants. For example, the National Energy Code of Canada for Buildings (NECB) takes a strict stance that occupants cannot be relied upon to improve energy performance: "provided it...is not dependent on occupant behaviour". In a less direct way, the American code gives a similar message: "In no case shall schedules differ where the controls are manual (e.g., manual operation of light switches or manual operation of windows)." The North American approach has a tendency to reward greater levels of automation rather than providing features such as manual operable windows and blinds that are understood to improve perceived control and comfort (e.g., de Dear, Brager et al. 1997). The German code states that boundary conditions related to occupants and the associated operations are aimed at neutral evaluation for the sole purpose of determining energy demand. Similarly, the Indian code acknowledges that actual energy use depends on occupant behavior and other factors that cannot be controlled for during design. France's code states that the provided schedules are as close as possible to average conditions, but that they cannot be expected to predict energy consumption during the operating phase of the building.

The English code also indirectly provides some hints at the underlying philosophy: "A centralised switch would be more reliable than depending on each individual occupant to switch off their (e.g.) computer." In a more specific example, for the performance path, the Canadian and American codes alike do not allow window shading devices to be modelled favorably (or at all) unless they are automated. This stance may be as a result of the concern that building owners are motivated to inflate predicted performance (Ouf and O'Brien 2018); occupants are not only uncertain but their positive behavior is difficult to 
disprove. For other codes, the target appears to be more realistic (e.g. partiallyclosed shades discussed in the previous section).

France's code has among the most optimistic outlooks of occupants, as it assumes manual systems are allowed to be controlled quite effectively. For instance, it assumes window shades are controlled linearly with respect to indoor illuminance, which is quite optimistic considering that shades often remain closed for days or weeks after they are initially closed (O'Brien et al. 2014). It also mandates that operable windows be closed below $8^{\circ} \mathrm{C}$ outdoor air temperature and increased open opening linearly till $16^{\circ} \mathrm{C}$, when the windows are fully open. Windows are only to be opened when mechanical cooling is off, whereas in reality occupants may leave windows open regardless of the mechanical system status. However, for heating systems, a window contact sensor must be provided (presumably to ensure that heating is deactivated or turned down if a window is open).

Numerous reviewed building energy codes (China, require occupancy sensing to turn off devices, thus implying a certain level of distrust (though realism) that occupants will turn it off prior to departure. Similarly, Brazil, Canada, and the US require motion sensors that turn lights off if a space is unoccupied. Canada's code gives some credit to occupants exploiting daylight, but still favours automation: "Research shows that, where a manual control is installed, the human eye acts as the photosensor and occupants take it upon themselves to lower electric lighting levels if sufficient daylight is available. However, manual controls are not as effective a means to save energy as automatic ones"

To require or disallow occupants to override automation systems implies a certain level of optimism or pessimism about occupants. Several codes (e.g., India) do not allow daylight-based lighting controls to be overridden by occupants. In contrast, the Danish code requires that occupants be able to override automated motorized windows. Similarly, the French code requires occupants to be able to override automated window shade controls. The Canadian and American codes allow overrides for various scheduled HVAC and lighting control modes, but the overrides are limited to one or two hours, depending on the instance.

\subsubsection{What are the most notable code requirements that should be considered elsewhere?}

This section is focused on exemplary code requirements that the authors encourage other codes to adopt.

Personal or high-resolution day/lighting and HVAC control. Several of the codes restrict the control zone size or area affected by HVAC and day/lighting systems to: 1 ) reduce the impact that one occupant has on another and 2) reduce energy wastage in partially or unevenly occupied buildings. Many codes (e.g. Australia, Canada, France, USA, Brazil) restrict lighting control zones to reduce the frequency of having partial or low occupancy but lights on. The New Zealand code simply requires natural ventilation for all buildings, while the Korean code encourages daylight. A seemingly unique requirement to UAE-1 is the requirement that window shades be no wider than 4 meters and directly controllable by occupants. This helps to ensure that occupants can somewhat personalize the level of daylight and glare they are subjected to. China requires 
that dissimilarly occupied spaces not be served by the same constant air volume (CAV) system. In Denmark, the compliance documentation must explain how individuals are provided with control via readjustment of diffusers for personal ventilation, temperature setpoint, operable windows, and the size of control zones and potential impact on other occupants. The Canadian code offers interesting insights: "Furthermore, occupants are much more likely to use manual controls if they have sole responsibility for a space than if they share a space: the [daylighting credit given for manual lighting controls in daylit spaces] for private enclosed offices is therefore [five times] higher than for other space types with manual controls." These requirements about spatial scope of controllability are particularly critical as we begin to recognize the diverse nature of individual occupant's schedules and preferences for indoor conditions (De Dear and Brager 2002, Wang, de Dear et al. 2018).

There is a limited mention of usability among the reviewed code requirements. A recurring requirement for numerous countries (Canada, US, and New Zealand) is that lights be visible from where they are controlled (e.g., from the light switch) unless safety would be at risk. In Denmark, indoor thermal conditions are required that be controlled in a simple way. Moreover, if one occupant can negatively affect another's thermal comfort, the range of controllability must be limited. In Canada, USA, India, and New Zealand, lights must be able to be seen from the location of the switch. This ensures that occupants are aware of the lights that they are controlling and are also more cognisant of leaving them on upon departure.

Numerous codes (e.g., Canada, Germany, UAE, USA, Austria) require demandcontrolled ventilation, though it is often limited to high-density and relatively large spaces. For instance, the American code requires DCV in spaces larger than $50 \mathrm{~m}^{2}$ and occupant densities above 0.25 person $/ \mathrm{m}^{2}$ (much higher than offices). In light of higher occupancy variations than the code schedules (see Phase 1) imply, DCV is often much more effective than predicted (O'Brien and Gunay 2019). In Switzerland, the regular occupancy schedule in private and shared offices is to be reduced by $20 \%$. This is sensible (and perhaps not enough), considering various monitoring studies, showing private offices are typically occupied only $50 \%$ as much as office building schedules would suggest (Duarte, Van Den Wymelenberg et al. 2013).

Several of the codes (e.g., Canada, USA) have strict rules against occupancy-on lighting controls (i.e., motion sensors tied to automatically turning on lights). This is particularly important for daylit spaces. Significant evidence (e.g., Reinhart and Voss 2003) shows that occupants are unlikely to turn on lights even if there is daylight illuminance that is an order of magnitude lower typical recommended levels. Gilani and O'Brien (2018) measured 62\% energy savings when occupancy-on lighting controls were replaced with manual-on lighting controls in perimeter offices. These same codes require lights to be automatically turned off after 20 minutes of absence.

Unique to the reviewed code requirements, the USA code requires centralized receptacle control. The requirement requires that at least half of receptacles in offices be turned off on a schedule or occupancy basis. Considering the growing share of plug loads in building energy end-use breakdowns, this appears to be an appropriate requirement. However, future research is required regarding 
occupants requiring remote desktop access and their ability to simply plug equipment into uncontrolled receptacles (Kaneda, Jacobson et al. 2010).

Finally, the UAE codes are significantly more advanced than the other reviewed codes regarding the interaction between the building and occupants. Designers are required to develop a guide for how to use and maintain the building. This includes: description of energy and water efficiency features and how occupants affect them; information on the building's IEQ and how it is measured and managed; materials and their environmental and social considerations; waste management strategy; recommendations for tenant fit-ups (e.g. lighting) and, details on availability of public transportation and bicycle facilities. Moreover, they must also provide a written plan for distributing the handbook to occupants. The UAE code also requires digital dashboards or the equivalent to provide feedback to occupants about building energy use and how they affect it. Documentation must be provided at the time of code compliance to show such digital interfaces and how they affect user experience.

\section{Discussion}

In general, the results of both phases of the research above indicate that occupant-related code requirements are quite simplistic. However, they vary greatly with regards to magnitudes (e.g. occupant density and schedule), simplicity (e.g. fixed schedule vs. dynamic models), optimism about occupant behavior, and scope. In this regard, it is important to note that one does not expect identical assumptions and modeling approaches with regard to occupants. On the contrary, from the authors' view, it would be ideal if each code reflects the unique working culture in its country to the extent possible. In particular, in case of a number of quantitative assumptions such as occupancy density or working hours, it is not surprising to see a large degree of variation across the codes commensurate with cultural and contextual factors. However, without a knowledge of the empirical basis behind the codes, the present study does not aim to explain the differences between the codes, but to put to the codes' approaches and assumptions in an international context to identify possibilities for improvements in future efforts. The last subsection above showed that there are numerous innovations in select countries that could be widely adopted by others. This section is focused on providing discussion on weaknesses of current codes and areas for improvement.

\subsection{Approaches to advance building codes}

O'Brien et al. (2018) provided a roadmap made specific recommendations for how codes could advance to better incorporate occupants. As previously discussed, the benefit of new code requirements must outweigh the costs. Key considerations include ability for code users to meet requirements, ability to enforce requirements, cost to comply, and potential negative impacts on policy and other unintended consequences. Six methods were suggested, as

summarized in the following subsections. They are approximately in the order of simplest to move complex.

\subsubsection{Add prescriptive requirements}

Prescriptive requirements, such as Canada and the USA's requirement that occupants can see the lights that light switch control, are most suitably added as 
prescriptive requirements. Such subtleties are difficult to model in building simulation. Additional areas that would be suitable for prescriptive requirements include usability of buildings and interfaces, occupant feedback, control zone sizes, requirements for window shades and operable windows, etc. To a large extent evidence and justification for new code requirements could be obtained from the literature, though likely focused studies are required as well.

\subsubsection{Add prescriptive requirements based on occupant simulation studies}

Similar to the point above, new prescriptive requirements could be added on the basis of simulation studies. For example, maximum lighting and HVAC control zone size requirements could be re-evaluated on the basis of more realistic office occupancy scenarios. For instance, O'Brien and Gunay (2019) used stochastic occupancy modelling to evaluate the impact of lighting control zone size, and consequently recommended that lighting control zones be reduced by a factor of five. Given the relatively advanced of stochastic occupant models, additional prescriptive requirements could be added to cover other domains, such as lighting, window shades, operable windows, receptacles, thermostats, etc.

\subsubsection{Update schedules based on new field studies}

While advanced occupant modelling may be beyond the comfort of code committees, schedules already exist in the majority of building codes (as indicated by Phase 1). Accordingly, schedules are a relatively low-risk way to update building codes. Its widely accepted that existing schedules are not very realistic. For example, occupancy is typically much lower than schedules indicate (Duarte, Van Den Wymelenberg et al. 2013). Societal trends, such as remote working, are expected to further increase this discrepancy, though this may be somewhat balanced by hotelling-style office management (Dwyer 2016).

Similarly, plug loads tend to be lower during the day (perhaps because of lower occupancy) and higher during the day than schedules would indicated (Gunay, O'Brien et al. 2016). While some extensive field studies have been performed to yield new schedules, further studies (e.g., Abushakra and Claridge 2001) should be performed in different building types and climates to build confidence in these schedules. Moreover, new building automation and sensing technologies (some of which are conveniently required by code, e.g., ASHRAE (2016)) should be employed for such studies to reduce costs and improve study size and duration.

\subsubsection{Develop schedules that cover a greater scope of occupant behaviour (e.g., window shades and blinds) based on detailed simulation studies}

Existing schedules tend to focus on non-adaptive occupant domains (e.g. occupancy, plug loads) and water, thermostat setpoints, and general lighting. However, window shades, operable windows, and other adaptive opportunities are generally absent by means of schedules. However, it would be feasible to build climate and building-specific schedules by running simulation studies that involve advanced occupant models. For example, Ouf, O'Brien et al. (2019) showed that semi-customized lighting and window shade schedules could be built by running numerous annual simulations. They used a decision tree and clustering to reduce simulation results to three different schedules: low, medium, and high. 


\subsubsection{Require multiple occupant scenarios to be simulated to better represent a range of possibilities}

An argument for using fixed and mandated schedules in building energy codes to model occupants is that while there is uncertainty about occupants, at least this approach can offer consistency (O'Brien, Gaetani et al. 2016). However, this approach risks causing designers to optimize buildings for one set of occupant assumptions, while neglecting other scenarios (e.g. low and partial occupancy) (O'Brien and Gunay 2019). One approach to address this is to mandate that several occupancy and occupant-related scenarios be modelled and then set constraints on the aggregate performance (e.g., the proposed building model must perform better than the reference building model for three different occupancy scenarios).

\subsubsection{Specify the occupant modeling approach required}

Finally, occupant-related requirements could be updated by mandating more advanced occupant modelling approaches. In particular, we recommend modelling approaches that demonstrate the adaptive nature of occupants and that recognize that better design can positively affect energy-related occupant behaviors. This particularly applied for key adaptive behaviors, such as operable windows, window shades, lighting, and thermostats. While not covered by the reviewed codes and standards, a notable example IES LM 83-2012 (IESNA 2012), which mandates for certain metric calculations that window shades be closed whenever a point on the workplane exceeds 1000 lux. Such rules would reward buildings with appropriately-sized windows and strategically-designed fixed shading that transmits comfortable levels of daylight.

While much of the recent scientific literature is focused on stochastic occupant models (e.g., Chen, Hong et al. 2018, D'Oca, Gunay et al. 2019), we argue that they are not suitable for building energy code purposes - at least for the foreseeable future. Stochastic occupant models yield a different result every time a simulation is run, which causes complexity when performance paths of building codes rely on single simulations. Moreover, the definition of these models (which usually involves a model form and coefficients) are not particularly transparent or easy to enforce, unlike basic rules-based models. Despite the trend towards agent-based stochastic models, the collected data that was used to build those models could also be re-used to develop simple rule-based models.

\subsection{Adding requirements for building usability}

One of the most notable omissions is requirements for occupant usability of buildings and their systems. In particular, this topic includes usability of interfaces (e.g., occupant instructions, feedback, location of interface, nature of interfaces). Usability may not appear to be energy-related, but it plays an important role in how occupants use energy in buildings (REF). While this is a gap in building energy codes, several standards (e.g., WELL, LEED) have addressed usability to some extent. These requirements could be incorporated into building energy codes (as they certainly indirectly affect energy ()). Some example requirements or items for credit in these standards include: 
- "Indicator lights at windows and/or online notifications signal to regular building occupants when outdoor air allows for open windows (with various IAQ and temperature conditions)" (Delos Living 2018). This requirement improves usability by providing cues to occupants about advantageous window opening actions, while still providing individual control to occupants (Ackerly and Brager 2011).

- "All operable windows in regularly occupied spaces comply with the following requirements:

- Provide enough space to permit occupants to approach and operate them (from both a standing and seated position).

o Are operable with one hand and with a closed fist and do not require tight grasping, pinching or twisting of the wrist.

- Require less than 22 N [5 lbs] of force to open (Delos Living 2018)." This requirement ensures that operable windows are not only provided to meet conditions but that they are usable even by occupants who are constrained to wheelchairs (American National Standards Institute 2009).

- "All regular building occupants have control over temperature through either:

o Thermostats Present within the thermal zone.

- Digital interface available on a computer or phone (Delos Living 2018)."

This requirement acknowledges the importance of personal control over temperature due to both the value of perceived control and the interoccupant differences in preferences for thermal conditions (Karjalainen 2009).

- "In all regularly occupied and shared spaces within the same heating or cooling zone, regular building occupants have access upon request to personal thermal comfort devices (e.g., personalized fans, heated/cooled chairs, and others, except combustion-based space heaters) that provide individual user control of air speed, air temperature and/or mean radiant temperature" (Delos Living 2018). Similar to the point above, this requirement recognizes the value of perceived control and the ability to customize thermal conditions for individual occupants. Moreover, these devices tend to be lower in energy-intensity than centralized HVAC systems.

- Similar to above, "Thermal comfort controls allow occupants, whether in individual spaces or shared multi-occupant spaces, to adjust at least one of the following in their local environment: air temperature, radiant temperature, air speed, and humidity" (U.S. Green Building Council 2019).

It is noteworthy that the above example requirements not only go into significantly more detail than is typically involved in building energy codes, but they are also supported by an extensive body of literature and ergonomics standards. However, we do not suggest that all requirements of WELL Building Standard and LEED should be adopted by building energy codes, as they have a different objective. Most building energy codes do not require measurement during operations; in contrast, WELL provides many credits for non-buildingrelated characteristics that are not covered by building energy codes (e.g. provision of blankets for occupants, restrictions on overnight flights for business travel) (Delos Living 2018). 


\section{Conclusion}

Considering the perceived impact of building energy codes and the corresponding simplicity of the way occupants are handled by them, this paper sought to provide an international review of occupant-related requirements building codes. In all 22 codes or standards were reviewed in two phases. Phase 1 focused on quantitative requirements relating to schedules, densities, and setpoints, as well as the general code objective, which revealed a wide range of occupant-related values concerning people density, lights, equipment and hot water use to standardize occupants in the path to meet performance targets such as secondary or primary energy use, emission rate or water consumption. The review showed considerable variations across the codes with regard to the occupancy, lighting and equipment power density values. While these could be partly assigned to cultural and contextual differences, the study put the occupant-related assumptions in an international context to facilitate the future efforts to develop occupant centric building energy codes. In particular, the study results suggest that the efforts to explicitly address occupant behaviour in the codes cannot overlook the implications of local contextual factors.

Phase 2 was focused on written code requirements. These code requirements were compared with the objective of identifying similarities, differences, and exemplary and noteworthy features.

The review concluded that while code requirements and underlying philosophies about occupants are diverse, they are generally quite simplistic and have not kept up with the scientific literature. For example, the majority of performance path (i.e. modelling-based) requirements do not adequately acknowledge design as a way to positively influence occupant behavior because they assume that behavior is the same in reference and design buildings (e.g., through schedules). Moreover, there is a lack of requirements for usability of buildings and their systems. Aside from perceived control for occupants and comfort implications, lack of usability could also have energy implications because occupants who cannot use buildings as they were intended are more likely to take energyadverse actions to restore their comfort.

For future research, we recommend the following foci:

- More field studies to collect long-term data in a variety of contexts (countries, building types) to improve confidence of both schedules (and densities) and potentially more advanced occupant models (e.g. agent based and dynamic).

- More field and simulation studies to support the updating of prescriptive requirements - especially regarding control zone sizes, control algorithms, and building system usability.

- An international committee to review all aspects of building energy codes, including occupant-related aspects. While there are some inherent differences between different regions' cultures and climates, a more consistent approach whereby the best alternatives are used, would be beneficial. In fact, International Energy Agency/Energy in Buildings and Communities has started a standing committee that is tasked with reviewing international building energy codes. 


\section{Acknowledgements}

The authors recognize the inspiration for this paper obtained from participation in IEA EBC Annex 79. The authors also acknowledge their respective funding sources.

\section{A Schedules of occupancy, light and equipment use}

Table A.1: The schedules of weekday occupancy for offices given in international building energy codes together with the average schedule (AVG)

\begin{tabular}{|c|c|c|c|c|c|c|c|c|c|c|c|c|c|c|c|}
\hline \multirow{2}{*}{$\begin{array}{l}\text { Hour } \\
\text { of } \\
\text { day }\end{array}$} & \multicolumn{15}{|c|}{ Fraction of maximum occupancy density } \\
\hline & AUS & BRA & CAN & CHE & $\mathrm{CHN}$ & DEU & DNK & ENG & FRA & IND & NOR & NZL & SGP & USA & AVG \\
\hline 1 & 0 & 0 & 0 & 0 & 0 & 0 & 0 & 0 & 0 & 0 & 0 & 0 & 0 & 0 & 0 \\
\hline 2 & 0 & 0 & 0 & 0 & 0 & 0 & 0 & 0 & 0 & 0 & 0 & 0 & 0 & 0 & 0 \\
\hline 3 & 0 & 0 & 0 & 0 & 0 & 0 & 0 & 0 & 0 & 0 & 0 & 0 & 0 & 0 & 0 \\
\hline 4 & 0 & 0 & 0 & 0 & 0 & 0 & 0 & 0 & 0 & 0 & 0 & 0 & 0 & 0 & 0 \\
\hline 5 & 0 & 0 & 0 & 0 & 0 & 0 & 0 & 0 & 0 & 0 & 0 & 0 & 0 & 0 & 0 \\
\hline 6 & 0 & 0 & 0 & 0 & 0 & 0 & 0 & 0 & 0 & 0 & 0 & 0 & 0 & 0 & 0 \\
\hline 7 & 0 & 0 & 0.1 & 0 & 0 & 0 & 0 & 0 & 0 & 0 & 0 & 0 & 0 & 0.1 & 0.01 \\
\hline 8 & 0.15 & 0 & 0.7 & 0.2 & 0.1 & 1 & 0 & 0.25 & 0 & 0.1 & 0.38 & 0.95 & 1 & 0.2 & 0.36 \\
\hline 9 & 0.6 & 1 & 0.9 & 0.6 & 0.5 & 1 & 1 & 0.5 & 0.57 & 0.2 & 0.38 & 0.95 & 1 & 0.95 & 0.72 \\
\hline 10 & 1 & 1 & 0.9 & 1 & 0.95 & 1 & 1 & 1 & 1 & 0.95 & 1 & 0.95 & 1 & 0.95 & 0.98 \\
\hline 11 & 1 & 1 & 0.9 & 1 & 0.95 & 1 & 1 & 1 & 1 & 0.95 & 1 & 0.95 & 1 & 0.95 & 0.98 \\
\hline 12 & 1 & 1 & 0.5 & 0.8 & 0.95 & 1 & 1 & 1 & 1 & 0.95 & 0.38 & 0.95 & 1 & 0.95 & 0.89 \\
\hline 13 & 1 & 1 & 0.5 & 0.4 & 0.8 & 1 & 1 & 0.75 & 0.57 & 0.95 & 0.38 & 0.95 & 1 & 0.5 & 0.77 \\
\hline 14 & 1 & 1 & 0.9 & 0.6 & 0.8 & 1 & 1 & 0.75 & 0.57 & 0.5 & 1 & 0.95 & 1 & 0.95 & 0.86 \\
\hline 15 & 1 & 1 & 0.9 & 1 & 0.95 & 1 & 1 & 1 & 1 & 0.95 & 1 & 0.95 & 1 & 0.95 & 0.98 \\
\hline 16 & 1 & 1 & 0.9 & 0.8 & 0.95 & 1 & 1 & 1 & 1 & 0.95 & 0.38 & 0.95 & 1 & 0.95 & 0.92 \\
\hline 17 & 1 & 1 & 0.7 & 0.6 & 0.95 & 1 & 1 & 1 & 1 & 0.95 & 0.38 & 0.95 & 1 & 0.95 & 0.89 \\
\hline 18 & 0.5 & 1 & 0.3 & 0.2 & 0.95 & 1 & 0 & 0.5 & 0.57 & 0.95 & 0 & 0.05 & 0 & 0.3 & 0.45 \\
\hline 19 & 0.15 & 0 & 0.1 & 0 & 0.3 & 0 & 0 & 0.25 & 0 & 0.39 & 0 & 0 & 0 & 0.1 & 0.09 \\
\hline 20 & 0.05 & 0 & 0.1 & 0 & 0.3 & 0 & 0 & 0 & 0 & $\begin{array}{l}0.1 \\
\end{array}$ & 0 & 0 & 0 & 0.1 & 0.05 \\
\hline 21 & 0.05 & 0 & 0.1 & 0 & 0 & 0 & 0 & 0 & 0 & 0.1 & 0 & 0 & 0 & 0.1 & 0.03 \\
\hline 22 & 0 & 0 & 0.1 & 0 & 0 & 0 & 0 & 0 & 0 & 0.1 & 0 & 0 & 0 & 0.1 & 0.02 \\
\hline 23 & 0 & 0 & 0 & 0 & 0 & 0 & 0 & 0 & 0 & 0 & 0 & 0 & 0 & 0.05 & 0 \\
\hline 24 & 0 & 0 & 0 & 0 & 0 & 0 & 0 & 0 & 0 & 0 & 0 & 0 & 0 & 0.05 & 0 \\
\hline
\end{tabular}

Table A.2: The schedules of weekday lighting power for offices given in international building energy codes together with the average schedule (AVG)

\begin{tabular}{|c|c|c|c|c|c|c|c|c|c|c|c|c|c|c|c|}
\hline \multirow{2}{*}{$\begin{array}{l}\text { Hour } \\
\text { of } \\
\text { day }\end{array}$} & \multicolumn{15}{|c|}{ Fraction of maximum lighting power } \\
\hline & AUS & BRA & CAN & $\mathrm{CHE}$ & $\mathrm{CHN}$ & DEU & DNK & ENG & FRA & IND & NOR & NZL & SGP & USA & AVG \\
\hline 1 & 0.1 & 0 & 0.05 & 0 & 0 & 0 & 0 & 0 & 0 & 0.05 & 0 & 0.05 & 0.1 & 0.05 & 0.03 \\
\hline 2 & 0.1 & 0 & 0.05 & 0 & 0 & 0 & 0 & 0 & 0 & 0.05 & 0 & 0.05 & 0.1 & 0.05 & 0.03 \\
\hline 3 & 0.1 & 0 & 0.05 & 0 & 0 & 0 & 0 & 0 & 0 & 0.05 & 0 & 0.05 & 0.1 & 0.05 & 0.03 \\
\hline 4 & 0.1 & 0 & 0.05 & 0 & 0 & 0 & 0 & 0 & 0 & 0.05 & 0 & 0.05 & 0.1 & 0.05 & 0.03 \\
\hline 5 & 0.1 & 0 & 0.05 & 0 & 0 & 0 & 0 & 0 & 0 & 0.05 & 0 & 0.05 & 0.1 & 0.05 & 0.03 \\
\hline 6 & 0.1 & 0 & 0.05 & 0 & 0 & 0 & 0 & 0 & 0 & 0.05 & 0 & 0.05 & 0.1 & 0.1 & 0.03 \\
\hline 7 & 0.1 & 0 & 0.3 & 0 & 0 & 0 & 0 & 0 & 0 & 0.1 & 0 & 0.05 & 0.1 & 0.1 & 0.05 \\
\hline 8 & 0.4 & 0 & 0.8 & 1 & 0.1 & 1 & 0 & 1 & 0 & 0.3 & 1 & 0.9 & 1 & 0.3 & 0.56 \\
\hline 9 & 0.8 & 1 & 0.9 & 1 & 0.5 & 1 & 1 & 1 & 1 & 0.9 & 1 & 0.9 & 1 & 0.65 & 0.90 \\
\hline 10 & 1 & 1 & 0.9 & 1 & 0.95 & 1 & 1 & 1 & 1 & 0.9 & 1 & 0.9 & 1 & 0.65 & 0.95 \\
\hline 11 & 1 & 1 & 0.9 & 1 & 0.95 & 1 & 1 & 1 & 1 & 0.9 & 1 & 0.9 & 1 & 0.65 & 0.95 \\
\hline 12 & 1 & 1 & 0.9 & 1 & 0.95 & 1 & 1 & 1 & 1 & 0.9 & 1 & 0.9 & 1 & 0.65 & 0.95 \\
\hline
\end{tabular}




\begin{tabular}{|c|c|c|c|c|c|c|c|c|c|c|c|c|c|c|c|}
\hline 13 & 1 & 1 & 0.9 & 1 & 0.8 & 1 & 1 & 1 & 1 & 0.9 & 1 & 0.9 & 1 & 0.55 & 0.93 \\
\hline 14 & 1 & 1 & 0.9 & 1 & 0.8 & 1 & 1 & 1 & 1 & 0.5 & 1 & 0.9 & 1 & 0.65 & 0.91 \\
\hline 15 & 1 & 1 & 0.9 & 1 & 0.95 & 1 & 1 & 1 & 1 & 0.9 & 1 & 0.9 & 1 & 0.65 & 0.95 \\
\hline 16 & 1 & 1 & 0.9 & 1 & 0.95 & 1 & 1 & 1 & 1 & 0.9 & 1 & 0.9 & 1 & 0.65 & 0.95 \\
\hline 17 & 1 & 1 & 0.8 & 1 & 0.95 & 1 & 1 & 1 & 1 & 0.9 & 1 & 0.9 & 1 & 0.65 & 0.94 \\
\hline 18 & 0.8 & 1 & 0.5 & 1 & 0.95 & 1 & 0 & 1 & 1 & 0.9 & 0 & 0.3 & 0.1 & 0.35 & 0.64 \\
\hline 19 & 0.6 & 0 & 0.3 & 0 & 0.3 & 0 & 0 & 1 & 0 & 0.5 & 0 & 0.3 & 0.1 & 0.3 & 0.24 \\
\hline 20 & 0.4 & 0 & 0.3 & 0 & 0.3 & 0 & 0 & 0 & 0 & 0.3 & 0 & 0.3 & 0.1 & 0.3 & 0.14 \\
\hline 21 & 0.2 & 0 & 0.1 & 0 & 0 & 0 & 0 & 0 & 0 & 0.3 & 0 & 0.3 & 0.1 & 0.2 & 0.09 \\
\hline 22 & 0.1 & 0 & 0.1 & 0 & 0 & 0 & 0 & 0 & 0 & 0.2 & 0 & 0.05 & 0.1 & 0.2 & 0.05 \\
\hline 23 & 0.1 & 0 & 0.05 & 0 & 0 & 0 & 0 & 0 & 0 & 0.1 & 0 & 0.05 & 0.1 & 0.1 & 0.04 \\
\hline 24 & 0.1 & 0 & 0.05 & 0 & 0 & 0 & 0 & 0 & 0 & 0.05 & 0 & 0.05 & 0.1 & 0.05 & 0.03 \\
\hline
\end{tabular}

Table A.3: The schedules of weekday equipment power for offices given in international building energy codes together with the average schedule (AVG)

\begin{tabular}{|c|c|c|c|c|c|c|c|c|c|c|c|c|c|c|c|}
\hline \multirow{2}{*}{$\begin{array}{l}\text { Hour } \\
\text { of } \\
\text { day }\end{array}$} & \multicolumn{15}{|c|}{ Fraction of maximum equipment power } \\
\hline & AUS & BRA & CAN & CHE & $\mathrm{CHN}$ & DEU & DNK & ENG & FRA & IND & NOR & NZL & SGP & USA & AVG \\
\hline 1 & 0.1 & 0 & 0.2 & 0.1 & 0 & 0 & 0 & 0.05 & 0.11 & 0 & 0 & 0.05 & 0.05 & 0.05 & 0.05 \\
\hline 2 & 0.1 & 0 & 0.2 & 0.1 & 0 & 0 & 0 & 0.05 & 0.11 & 0 & 0 & 0.05 & 0.05 & 0.05 & 0.05 \\
\hline 3 & 0.1 & 0 & 0.2 & 0.1 & 0 & 0 & 0 & 0.05 & 0.11 & 0 & 0 & 0.05 & 0.05 & 0.05 & 0.05 \\
\hline 4 & 0.1 & 0 & 0.2 & 0.1 & 0 & 0 & 0 & 0.05 & 0.11 & 0 & 0 & 0.05 & 0.05 & 0.05 & 0.05 \\
\hline 5 & 0.1 & 0 & 0.2 & 0.1 & 0 & 0 & 0 & 0.05 & 0.11 & 0 & 0 & 0.05 & 0.05 & 0.05 & 0.05 \\
\hline 6 & 0.1 & 0 & 0.2 & 0.1 & 0 & 0 & 0 & 0.05 & 0.11 & 0 & 0 & 0.05 & 0.05 & 0.1 & 0.05 \\
\hline 7 & 0.1 & 0 & 0.3 & 0.1 & 0 & 0 & 0 & 0.05 & 0.11 & 0 & 0 & 0.05 & 0.05 & 0.1 & 0.06 \\
\hline 8 & 0.25 & 0 & 0.8 & 0.2 & 0.1 & 1 & 0 & 1 & 0.11 & 0 & 0.38 & 0.9 & 1 & 0.3 & 0.43 \\
\hline 9 & 0.7 & 1 & 0.9 & 0.6 & 0.5 & 1 & 1 & 1 & 0.55 & 0.1 & 0.38 & 0.9 & 1 & 0.9 & 0.75 \\
\hline 10 & 1 & 1 & 0.9 & 0.8 & 0.95 & 1 & 1 & 1 & 1 & 0.9 & 1 & 0.9 & 1 & 0.9 & 0.95 \\
\hline 11 & 1 & 1 & 0.9 & 1 & 0.95 & 1 & 1 & 1 & 1 & 0.9 & 1 & 0.9 & 1 & 0.9 & 0.97 \\
\hline 12 & 1 & 1 & 0.9 & 0.8 & 0.95 & 1 & 1 & 1 & 1 & 0.9 & 0.38 & 0.9 & 1 & 0.9 & 0.91 \\
\hline 13 & 1 & 1 & 0.9 & 0.4 & 0.5 & 1 & 1 & 1 & 1 & 0.9 & 0.38 & 0.9 & 1 & 0.8 & 0.84 \\
\hline 14 & 1 & 1 & 0.9 & 0.6 & 0.5 & 1 & 1 & 1 & 1 & 0.8 & 1 & 0.9 & 1 & 0.9 & 0.90 \\
\hline 15 & 1 & 1 & 0.9 & 1 & 0.95 & 1 & 1 & 1 & 1 & 0.9 & 1 & 0.9 & 1 & 0.9 & 0.97 \\
\hline 16 & 1 & 1 & 0.9 & 0.8 & 0.95 & 1 & 1 & 1 & 1 & 0.9 & 0.38 & 0.9 & 1 & 0.9 & 0.91 \\
\hline 17 & 1 & 1 & 0.9 & 0.6 & 0.95 & 1 & 1 & 1 & 1 & 0.9 & 0.38 & 0.9 & 1 & 0.9 & 0.89 \\
\hline 18 & 0.6 & 1 & 0.5 & 0.2 & 0.95 & 1 & 0 & 1 & 0.55 & 0.9 & 0 & 0.3 & 0.05 & 0.5 & 0.54 \\
\hline 19 & 0.25 & 0 & 0.3 & 0.1 & 0.3 & 0 & 0 & 1 & 0.11 & 0.5 & 0 & 0.3 & 0.05 & 0.3 & 0.23 \\
\hline 20 & 0.15 & 0 & 0.3 & 0.1 & 0.3 & 0 & 0 & 1 & 0.11 & 0.1 & 0 & 0.3 & 0.05 & 0.3 & 0.19 \\
\hline 21 & 0.15 & 0 & 0.2 & 0.1 & 0 & 0 & 0 & 0.05 & 0.11 & 0.1 & 0 & 0.3 & 0.05 & 0.2 & 0.09 \\
\hline 22 & 0.1 & 0 & 0.2 & 0.1 & 0 & 0 & 0 & 0.05 & 0.11 & 0 & 0 & 0.05 & 0.05 & 0.2 & 0.06 \\
\hline 23 & 0.1 & 0 & 0.2 & 0.1 & 0 & 0 & 0 & 0.05 & 0.11 & 0 & 0 & 0.05 & 0.05 & 0.1 & 0.05 \\
\hline 24 & 0.1 & 0 & 0.2 & 0.1 & 0 & 0 & 0 & 0.05 & 0.11 & 0 & 0 & 0.05 & 0.05 & 0.05 & 0.05 \\
\hline
\end{tabular}

\section{References}

Abuimara, T., W. O'Brien, B. Gunay, A. Abdelalim, M. Ouf and S. Gilani (2018).

Modelling Occupants in Buildings: Stakeholders' Workshop on Current Barriers,

Challenges and Needs. eSim 2018. Montreal, QC May 8-9.

Abushakra, B. and D. Claridge (2001). Accounting for the occupancy variable in inverse building energy baselining models, Energy Systems Laboratory, Texas

A\&M University.

Ackerly, K. C. and G. Brager (2011). Occupant response to window control

signaling systems. University of California, Berkeley, Center for the Built Environment. 
American National Standards Institute (2009). Accessible and usable buildings and facilities - ICC 1111.1-2009 International Code Council.

American Society of Heating Refrigerating and Air-conditioning Engineers (ASHRAE) (2016). ANSI/ASHRAE/IESNA Standard 90.1-2016: Energy standard for buildings except for low-rise residential buildings.

Aroonruengsawat, A., M. Auffhammer and A. H. Sanstad (2012). "The impact of state level building codes on residential electricity consumption." Energy JournalCleveland 33(1): 31.

Chen, Y., T. Hong and X. Luo (2018). An agent-based stochastic occupancy simulator. Building Simulation, Springer.

Chirarattananon, S., P. Chaiwiwatworakul, V. D. Hien, P. Rakkwamsuk and K. Kubaha (2010). "Assessment of energy savings from the revised building energy code of Thailand." Energy 35(4): 1741-1753.

D'Oca, S., H. B. Gunay, S. Gilani and W. O'Brien (2019). "Critical review and illustrative examples of office occupant modelling formalisms." Building Services Engineering Research and Technology 0(0): 0143624419827468.

de Dear, R., G. S. Brager and D. Cooper (1997). Developing an Adaptive Model of Thermal Comfort and Preference. Final Report on ASHRAE Research Project 884. Sydney, Macquarie University.

De Dear, R. J. and G. S. Brager (2002). "Thermal comfort in naturally ventilated buildings: revisions to ASHRAE Standard 55." Energy and buildings 34(6): 549-

561.

Delos Living (2018). WELL Building Standard v2. New York, NC

Deru, M., K. Field, D. Studer, K. Benne, B. Griffith, P. Torcellini, B. Liu, M. Halverson, D. Winiarski and M. Rosenberg (2011). Commercial Reference Building Models of the National Building Stock, US Department of Energy. Duarte, C., K. Van Den Wymelenberg and C. Rieger (2013). "Revealing occupancy patterns in an office building through the use of occupancy sensor data." Energy and Buildings 67: 587-595.

Dwyer, A. (2016). With hot-desking, not all employees are sitting pretty. The Globe and Mail. Toronto.

Evans, M., V. Roshchanka and P. Graham (2017). "An international survey of building energy codes and their implementation." Journal of Cleaner Production 158: 382-389.

Fabi, V., R. V. Andersen, S. Corgnati and B. W. Olesen (2012). "Occupants' window opening behaviour: A literature review of factors influencing occupant behaviour and models." Building and Environment 58(December): 188-198. Feng, X., D. Yan and T. Hong (2015). "Simulation of occupancy in buildings." Energy and Buildings 87: 348-359.

Fouquet, R. and P. J. Pearson (2012). "The long run demand for lighting: elasticities and rebound effects in different phases of economic development." Economics of Energy \& Environmental Policy 1(1): 83-100.

Gilani, S. and W. O'Brien (2018). "A preliminary study of occupants' use of manual lighting controls in private offices: A case study." Energy and Buildings 159: 572-586.

Goins, J., C. Chun and H. Zhang (2013). "User perspectives on outdoor noise in open-plan offices with operable windows." Architectural Science Review 56(1): 42-47.

Gram-Hanssen, K. (2010). "Residential heat comfort practices: understanding users." Building Research \& Information 38(2): 175-186.

Gunay, H. B., W. O'Brien, I. Beausoleil-Morrison and S. Gilani (2016). "Modeling plug-in equipment load patterns in private office spaces." Energy and Buildings 121: 234-249. 
Hafer, M. (2017). "Quantity and electricity consumption of plug load equipment on a university campus." Energy Efficiency 10(4): 1013-1039.

Haldi, F. and D. Robinson (2011). "The impact of occupants' behaviour on building energy demand." Lournal of Building Performance Simulation 4(4): 323338.

Hoes, P., J. L. M. Hensen, M. G. L. C. Loomans, B. de Vries and D. Bourgeois (2009). "User behavior in whole building simulation." Energy and Buildings 41(3): 295-302.

Hong, T. and H.-W. Lin (2013). Occupant behavior: impact on energy use of private offices, Ernest Orlando Lawrence Berkeley National Laboratory, Berkeley, CA (US).

IESNA (2012). LM-83-12 IES Spatial Daylight Autonomy (sDA) and Annual Sunlight Exposure (ASE). IESNA Lighting Measurement. New York, NY.

Jacobsen, G. D. and M. J. Kotchen (2013). "Are building codes effective at saving energy? Evidence from residential billing data in Florida." Review of Economics and Statistics 95(1): 34-49.

Kaneda, D., B. Jacobson, P. Rumsey and R. Engineers (2010). Plug load reduction: The next big hurdle for net zero energy building design. ACEEE Summer Study on Energy Efficiency in Buildings, Pacific Grove, CA.

Karjalainen, S. (2009). "Thermal comfort and use of thermostats in Finnish homes and offices." Building and Environment 44(6): 1237-1245.

Laustsen, J. (2008). "Energy Efficiency Requirements in Building Codes, Energy Efficiency Policies for New Buildings: IEA Information Paper." Support of the G8 Plan of Action.

Misuriello, H., S. Penney, M. Eldridge and B. Foster (2010). "Lessons learned from building energy code compliance and enforcement evaluation studies."

Proceedings of the 2010 ACEEE Summer Study on Energy Efficiency in Buildings 8: 245-255.

National Research Council Canada (NRC) (2017). National Energy Code of Canada for Buildings 2017. Ottawa, Canada, Canada.

O'Brien, W. and H. B. Gunay (2019). "Do building energy codes adequately reward buildings that adapt to partial occupancy?" Science and Technology for the Built Environment: 1-14.

O'Brien, W., I. Gaetani, S. Gilani, S. Carlucci, P.-J. Hoes and J. Hensen (2016). "International survey on current occupant modelling approaches in building performance simulation." Journal of Building Performance Simulation: 1-19. O'Brien, W. and H. B. Gunay (2015). "Mitigating office performance uncertainty of occupant use of window blinds and lighting using robust design." Building Simulation 8(6): 621-636.

O'Brien, W., H. B. Gunay, F. Tahmasebi and A. Mahdavi (2017). "A preliminary study of representing the inter-occupant diversity in occupant modelling." Journal of Building Performance Simulation 10(5-6): 509-526.

Ouf, M. and W. O'Brien (2018). Can we game code compliance through occupant modeling? . ASHRAE Journal.

Ouf, M., W. O'Brien and B. Gunay (2019). "A method to generate design-sensitive occupant-related schedules for building performance simulations." Science and Technology for the Built Environment 25(2): 221-232.

Park, J. Y. and Z. Nagy (2018). "Comprehensive analysis of the relationship between thermal comfort and building control research - A data-driven literature review." Renewable and Sustainable Energy Reviews 82: 2664-2679.

Pérez-Lombard, L., J. Ortiz, J. F. Coronel and I. R. Maestre (2011). "A review of HVAC systems requirements in building energy regulations." Energy and Buildings 43(2): 255-268. 
Reinhart, C. F. (2004). "Lightswitch-2002: a model for manual and automated control of electric lighting and blinds." Solar Energy 77(1): 15-28.

Reinhart, C. F. and K. Voss (2003). "Monitoring manual control of electric lighting and blinds." Lighting Research \& Technology 35(3): 243-260.

Tahmasebi, F. and A. Mahdavi (2017). "The sensitivity of building performance simulation results to the choice of occupants' presence models: a case study." Journal of Building Performance Simulation 10(5-6): 625-635.

U.S. Green Building Council (2019). LEED v4.1 Building Design and Construciton. Van Den Wymelenberg, K. (2012). "Patterns of occupant interaction with window blinds: A literature review." Energy and Buildings 51: 165-176.

Wagner, A. and L. O’Brien (2018). Proposal: IEA EBC Annex 79: Occupant behaviour-centric building design and operation, Proposal.

Wang, Z., R. de Dear, M. Luo, B. Lin, Y. He, A. Ghahramani and Y. Zhu (2018). "Individual difference in thermal comfort: A literature review." Building and

Environment 138: 181-193.

Yan, D. and T. Hong (2018). EBC Annex 66 Final Report - Definition and simulation of occupant behavior in buildings.

Yan, D., T. Hong, B. Dong, A. Mahdavi, S. D'Oca, I. Gaetani and X. Feng (2017). "IEA EBC Annex 66: Definition and simulation of occupant behavior in buildings." Energy and Buildings 156: 258-270. 